\title{
NF-кB-mediated expression of MAPK phosphatase- 1 is an early step in desensitization to TLR ligands in enterocytes
}

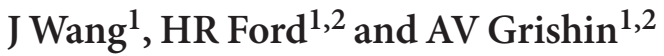

Toll-like receptor (TLR) signaling in naive enterocytes is rapidly inhibited, leading to the establishment of tolerance. To gain insight into tolerance at the level of the proinflammatory mitogen-activated protein kinase (MAPK) p38, we characterized TLR-mediated induction of the p38-specific phosphatase MKP-1. In cultured enterocytes, ligands of TLR3, TLR4, TLR5, and TLR9, but not TLR2, induce MKP-1 at 30-60 min, coincident with dephosphorylation of p38 following the peak of TLR ligand-induced phosphorylation. Induction of MKP-1 is blocked by inhibitors of nuclear factor (NF)- $\kappa B$, but not of MAPK. Small interfering RNA knockdown of IkB $\alpha$ prolongs the expression of MKP-1.

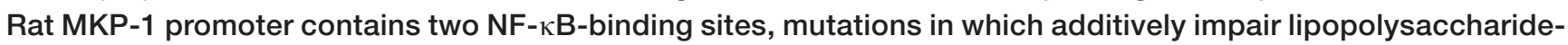
induced transcription from the MKP-1 promoter. In the intestine, MKP-1 is expressed in the crypts, the epithelial compartment that also displays bacteria-dependent activating phosphorylation of $\mathrm{p} 38$. Thus, NF- $\kappa \mathrm{B}-d e p e n d e n t$ expression of MKP-1 may contribute, by desensitization of $\mathrm{p} 38$, to the rapid establishment of unresponsiveness to several TLR ligands in enterocytes.

\section{INTRODUCTION}

Similar to several other cell types, enterocytes possess elements of innate immunity including Toll-like receptors (TLR) as well as nuclear factor (NF)- $\mathrm{\kappa B}$ and mitogen-activated protein kinase (MAPK) signaling pathways that facilitate recognition of microbial components. Upon challenge with TLR ligands, enterocytes produce inflammatory cytokines, chemokines, prostanoids, and defensins. ${ }^{1,2}$ TLR signaling in the gut is critically important for the maintenance of intestinal homeostasis. ${ }^{3}$

Although the intestinal epithelium is potentially responsive to TLR ligands, commensal bacteria do not cause exuberant inflammation under normal conditions. Dramatic inflammatory response in the epithelium is avoided by rapid downregulation of inflammatory signaling, ultimately leading to the state of hyporesponsiveness to commensal microbiota that does not allow exuberant inflammation, yet permits benign, homeostatic proinflammatory responses. ${ }^{4}$ The intestinal epithelium of neonates and germ-free animals is sensitive to TLR ligands; however, this sensitivity is blunted shortly after bacterial colonization. ${ }^{5,6}$ The mechanisms of epithelial desensitization to TLR ligands are not fully understood. Several studies have implicated the downregulation of TLRs and their coreceptors. ${ }^{7-9}$ Downregulation of responses to TLR ligands in colonocytes may result from induction of the TLR-interacting inhibitory protein Tollip. ${ }^{10,11}$ Enterocyte hyporesponsiveness to lipopolysaccharide (LPS) and flagellin may be associated with posttranslational inhibition of interleukin (IL) receptorassociated kinases- 1 and -4 , which are the mediators of TLR signaling. ${ }^{6,12}$ Attenuated responses to luminal flagellin may result from basolateral (as opposed to apical) localization of its cognate receptor, TLR5. ${ }^{13}$ Tolerance of enterocytes to luminal LPS may be associated with the removal of TLR4 from the apical aspect. ${ }^{14}$ Apical, but not basolateral, stimulation with CpG DNA promotes tolerance to this TLR9 ligand. ${ }^{15}$ Despite these findings, the definitive mechanisms that desensitize the intestinal epithelium to commensal bacteria, yet allow benign inflammatory responses, remain elusive. ${ }^{4}$

In our previous report, we have shown that development of profound and long-lasting tolerance to TLR ligands LPS and CpG DNA in enterocytes is caused by induction of the ubiquitin-editing enzyme A20. ${ }^{16}$ The key role of A20 in tolerance to the intestinal microbiota is also supported by severe intestinal

\footnotetext{
${ }^{1}$ Division of Pediatric Surgery, Childrens Hospital Los Angeles, Los Angeles, California, USA. ²Department of Surgery, University of Southern California, Los Angeles, California, USA. Correspondence: AV Grishin (agrishin@chla.usc.edu) 
inflammation in A20 knockout mice. ${ }^{17,18}$ By deubiquitinating its critical targets in TLR signaling pathways, A20 interrupts signals that lead to activation of NF- $\kappa \mathrm{B}$ and $\mathrm{p} 38$. As the half-life of the A20 protein is comparable with enterocyte life span, expression of A20 causes long-lasting tolerance to TLR ligands. ${ }^{16}$ However, induced expression of A20 does not explain rapid dephosphorylation of MAPKs, particularly p38, which precedes accumulation of the A20 protein in LPS-treated enterocytes. ${ }^{19,20}$ In this study, we report that in enterocytes, ligands of TLR3, TLR4, TLR5, and TLR9, but not TLR2, rapidly induce MAPK phosphatase-1 (MKP-1), the dual specificity phosphatase that preferentially dephosphorylates $\mathrm{p} 38$, by NF- $\mathrm{\kappa B}$-mediated activation of transcription from the MKP-1 promoter. We also show that MKP-1 expression temporally coincides with the deactivation phase during transient TLR ligand-induced activating phosphorylation of p38. In the small intestine, MKP-1 is expressed in the crypts, the epithelial compartment that also displays bacteriadependent activating phosphorylation of $\mathrm{p} 38$. Our data indicate that NF- $\mathrm{KB}$-mediated expression of MKP-1 may have a role in the rapid establishment of tolerance to a subset of TLR ligands in enterocytes. The delay of MKP-1 expression relative to the surge in the activating phosphorylation of p38 may allow limited p38-dependent homeostatic proinflammatory signaling in the intestinal epithelium.

\section{RESULTS \\ p38 MAPK is transiently activated upon exposure of enterocytes to TLR ligands}

p38 MAPK mediates inflammatory responses in enterocytes including upregulation of cyclooxygenase-2 (COX-2), a key enzyme in the biosynthesis of prostanoids ${ }^{20}$ and production of the inflammatory cytokine IL-8. ${ }^{21,22}$ Previously, we have reported a rapid but transient increase in activating phosphorylation of p38 in LPS-stimulated IEC-6 enterocytes. ${ }^{19}$ We also described transient LPS-induced activation of p38 in the naive intestinal mucosa ex vivo. ${ }^{20}$ The time course of LPS-induced p38 activation in three other enterocyte cell lines, namely IEC18 , SW480, and RIE-1, is very similar to that in IEC-6 cells (Figure 1a). Several other TLR ligands including CpG DNA, flagellin, and dsRNA, recognized by TLR9, TLR5, and TLR3, respectively, also caused transient activation of p38 peaking at 5-30 min (Figure 1b). However, TLR2 ligands, lipoteichoic acid (Figure 1b), peptydoglycan, and tripalmityl cysteine-serine-(lysine $)_{4}\left(\mathrm{Pam}_{3} \mathrm{CSK}_{4}\right.$, Figure $\mathbf{2} \mathbf{a}$ and $\left.\mathbf{b}\right)$, caused relatively

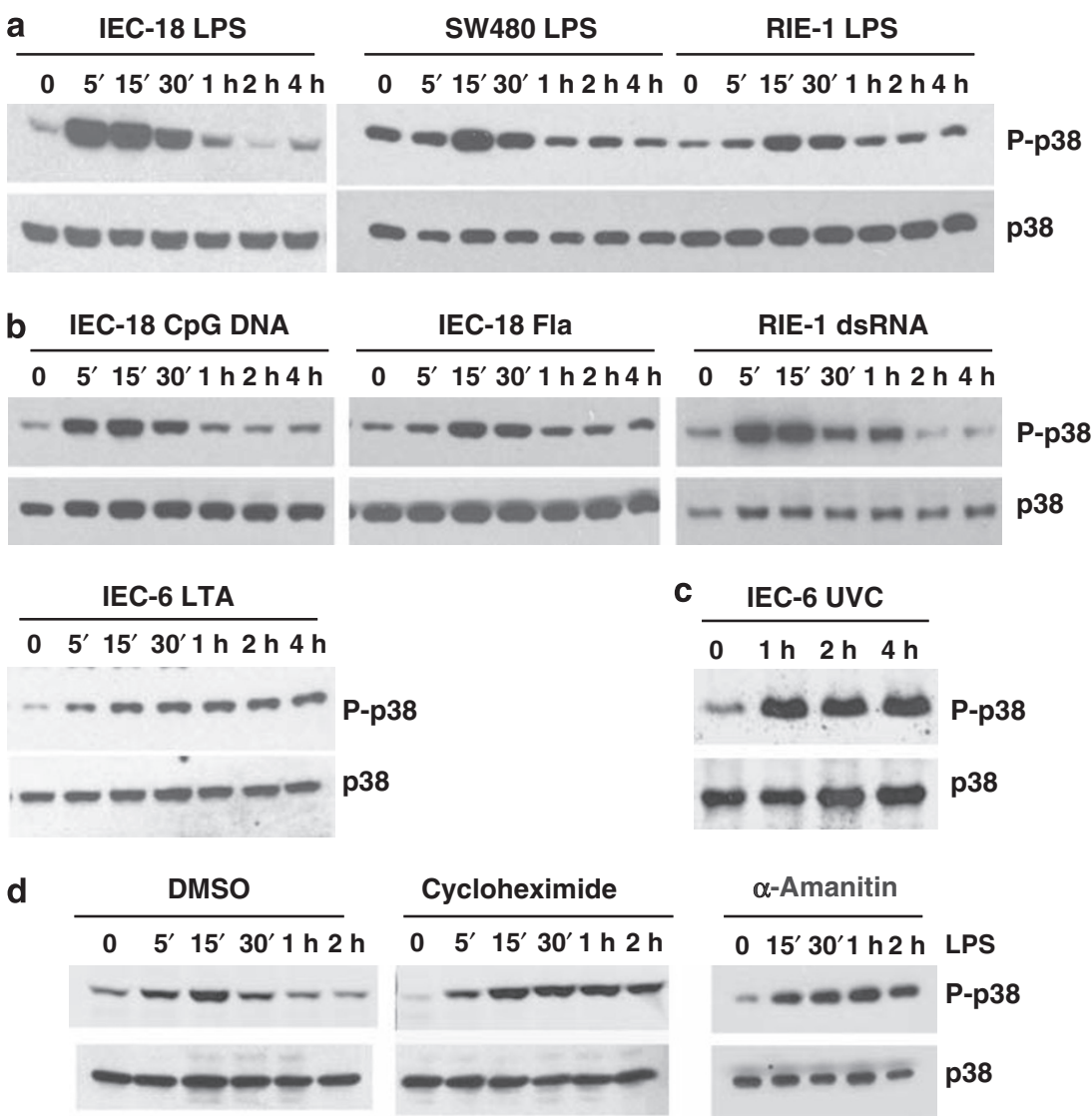

Figure 1 Time course of p38 activation in enterocyte cell lines. (a) Time course of p38 phosphorylation induced by $200 \mathrm{ng} \mathrm{ml}^{-1}$ of LPS in IEC18, SW480, and RIE-1 cells. (b) Time course of p38 activation in IEC-18 cells treated with unmethylated CpG DNA or flagellin at $50 \mu \mathrm{gml} \mathrm{I}^{-1}$ and $100 \mathrm{ng} \mathrm{ml}^{-1}$, respectively; in RIE-1 cells treated with $50 \mu \mathrm{g} \mathrm{ml}^{-1}$ poly (I:C); and in IEC-6 cells treated with $10 \mu \mathrm{g} \mathrm{ml}{ }^{-1}$ lipoteichoic acid. (c) Time course of p38 phosphorylation in IEC-6 cells exposed to $40 \mathrm{~mJ} \mathrm{~cm}^{-2}$ ultraviolet C (UVC) and incubated in growth medium for indicated time. (d) Time course of LPS-induced p38 phosphorylation in IEC-6 cells pretreated for 20 min with $10 \mu \mathrm{m}$ cycloheximide, $10 \mu \mathrm{M} \alpha$-amanitin, or equivalent amount of DMSO. Data are representative of at least three independent experiments. DMSO, dimethyl sulfoxide; LPS, lipopolysaccharide. 

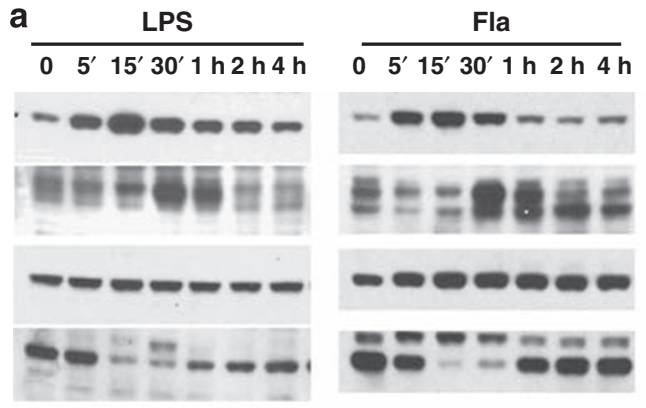

b

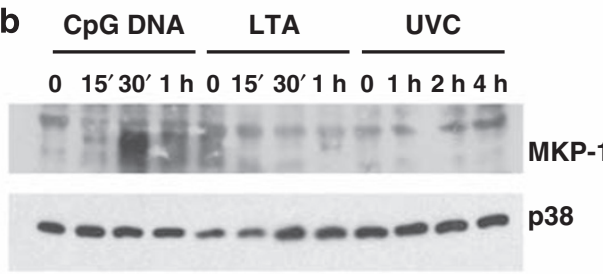

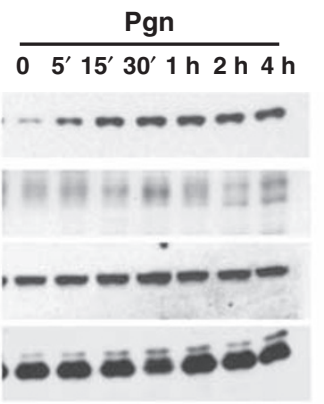

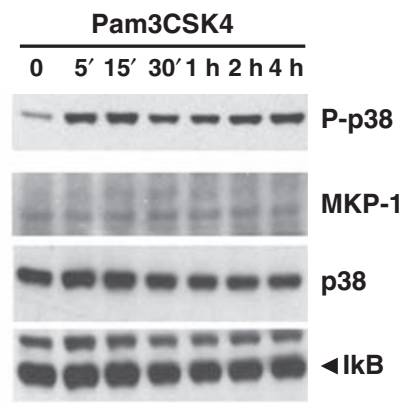

C
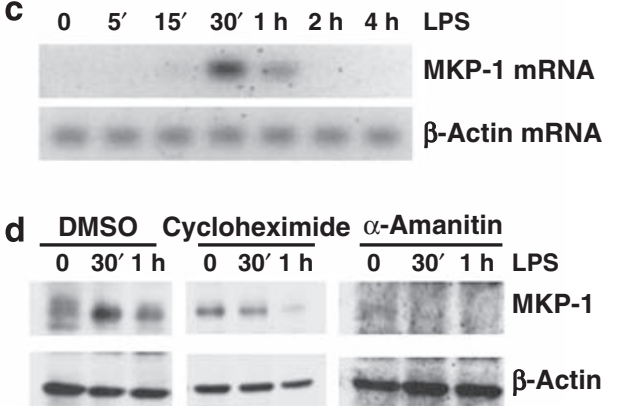

Figure 2 Time course of inflammatory and stress responses in enterocytes. (a) Levels of phospho-p38, MKP-1, p38, and IkB $\alpha$ in IEC-6 cells treated with LPS, flagellin, $20 \mu \mathrm{g} \mathrm{ml}^{-1}$ peptydoglycan, or $50 \mu \mathrm{g} \mathrm{ml}^{-1} \mathrm{Pam}_{3} \mathrm{CSK}_{4}$ for the indicated time. Arrowhead indicates IkB $\alpha$ band; the band above it is due to nonspecific reactivity of a particular batch of IkB $\alpha$ Ab. (b) Time course of MKP-1 protein expression in IEC-6 cells treated with CpG DNA, lipoteichoic acid (LTA), or UVC. (c) Northern blot for MKP-1 and $\beta$-actin mRNAs in IEC-6 cells treated with LPS for the indicated time. (d) Levels of MKP-1 and $\beta$ actin proteins in IEC- 6 cells pretreated with cycloheximide, $\alpha$-amanitin, or equivalent amount of DMSO, and treated with LPS for indicated time. All data are representative of at least three independent experiments. Ab, antibody; DMSO, dimethyl sulfoxide; LPS, lipopolysaccharide; MKP, mitogenactivated protein kinase phosphatase-1.

weak, but sustained activation of p38. Sustained activation of p38 also occurred in response to ultraviolet C (UVC) (Figure 1c). According to these data, $\mathrm{p} 38$ can be activated in enterocytes either transiently or in a sustained manner, depending on the nature of the activating stimulus.

A remarkably fast dephosphorylation of $\mathrm{p} 38$ following activation by several TLR ligands suggests concomitant induction of deactivating factor(s). To test the possibility of LPS-induced expression of $\mathrm{p} 38$-deactivating proteins, we examined the time course of LPS-induced p38 phosphorylation in the presence of $\alpha$-amanitin or cycloheximide, inhibitors of mRNA or protein synthesis. Neither inhibitor activated p38; however, each changed the transient mode of LPS-induced activation to the sustained (Figure 1d), indicating that de novo gene expression is necessary for p38 activation to be transient.

\section{Deactivation of p38 MAPK closely follows induction of MKP-1 in LPS-treated enterocytes}

As multiple studies have implicated MKP- 1 as an enzyme that preferentially dephosphorylates $\mathrm{p} 38$ during innate immune responses, ${ }^{23}$ we hypothesized that MKP-1 induction is involved in the rapid dephosphorylation of p38 in LPS-treated enterocytes. Indeed, TLR ligands that cause transient activation of $\mathrm{p} 38$, including LPS, flagellin, and CpG DNA, all induced MKP-1 in IEC- 6 cells with the peak at 30-60 min, which is coincident with the decrease in TLR ligand-induced p38 phosphorylation. By contrast, TLR2 ligands that caused relatively weak, but sustained activation of $\mathrm{p} 38$, as well as UVC that causes strong sustained activation, failed to appreciably induce MKP- 1 in enterocyte cell lines within $4 \mathrm{~h}$ of treatment (Figure 2a and $\mathbf{b}$ shows data for IEC- 6 and IEC- 18 cells; similar data for RIE- 1 and SW480 cells are not shown). The increase in MKP-1 protein levels in LPS-treated cells was coincident with the induction of MKP-1 mRNA (Figure 2c, Supplementary Figure S1 online), and was abrogated by pretreatment with $\alpha$-amanitin or cycloheximide (Figure 2d), which implicates transcriptional and translational expression of MKP-1.

If MKP-1 induction is responsible for the deactivation of $\mathrm{p} 38$ following TLR ligand-induced activation, inhibition of MKP-1 should prolong TLR ligand-induced phosphorylation of $\mathrm{p} 38$, whereas high levels of MKP-1 should attenuate it. To establish a causal relationship between MKP- 1 expression and p38 deactivation, we examined LPS-induced phosphorylation of p38 in cells treated with the specific MKP-1 inhibitor sanguinarine ${ }^{24}$ or MKP-1 small interfering RNA (siRNA) and in cells expressing MKP-1 ectopically. As sanguinarine rapidly kills cells at concentrations that inhibit MKP-1, this drug was used in combination with $\mathrm{N}$-acetyl cysteine, which mitigates cytotoxicity. ${ }^{25}$ Sanguinarine did not affect LPS-induced expression of MKP-1; however, it dramatically prolonged the LPS-induced phosphorylation of p38 (Figure 3a). p38 activation was also prolonged by MKP-1 siRNA (Figure 3b, Supplementary Figure S2 online). By contrast, transfection of IEC-6 cells with pFLAG-MKP-1 markedly attenuated LPS-induced phosphorylation of p38 (Figure 3c). Thus, MKP-1 downregulates LPS-activated p38 in enterocytes. 
a

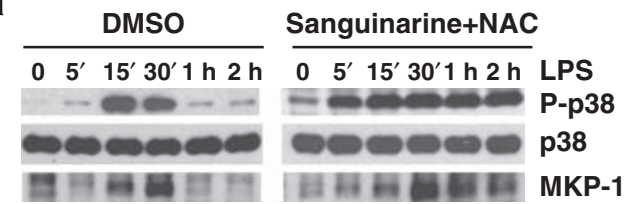

b

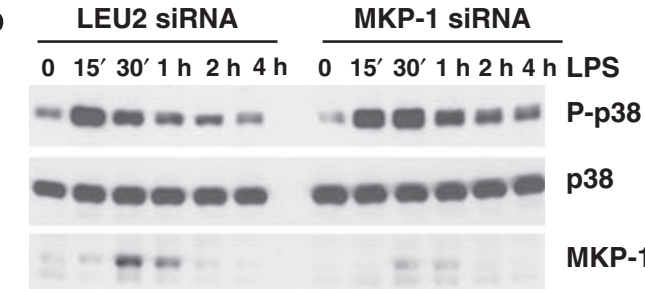

C

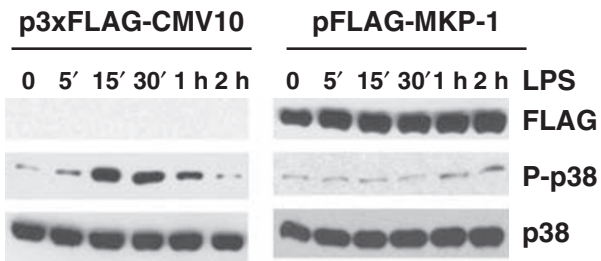

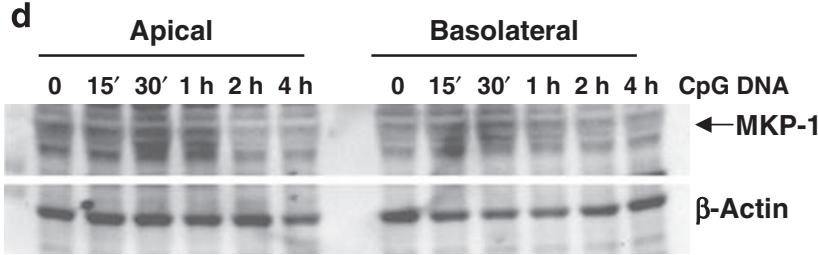

e

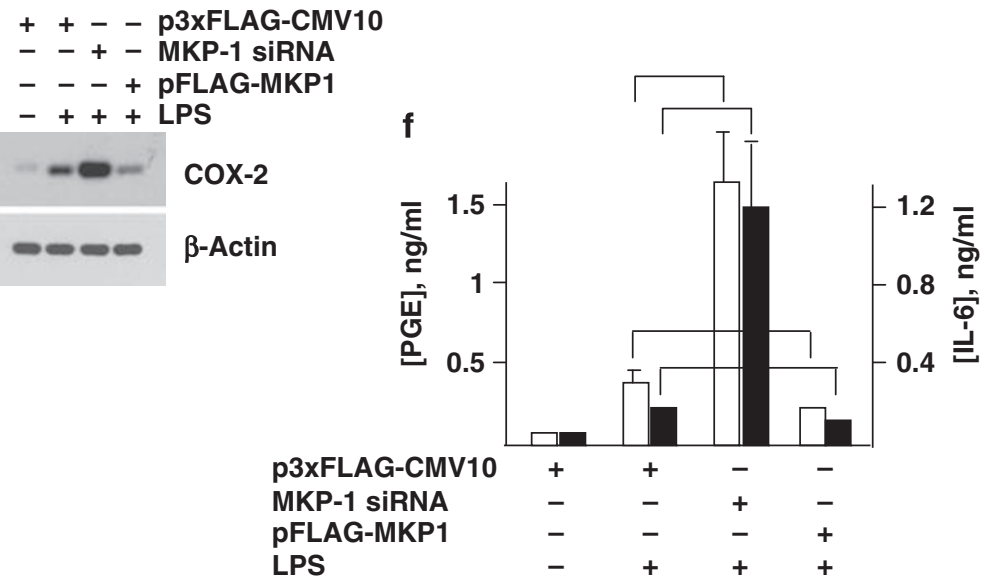

Figure 3 Effects of MKP-1 inhibition or ectopic expression on phosphorylation of p38, expression of COX-2, production of PGE, and secretion of IL-6. (a) Levels of phospho-p38 and MKP-1 in IEC-6 cells pretreated with $25 \mu \mathrm{M}$ sanguinarine $+2 \mathrm{mM}$-acetyl cysteine (NAC), or equivalent amount of DMSO, and treated with LPS for the indicated time. (b) Levels of phospho-p38 and MKP-1 in IEC-6 cells transfected with LEU2 or MKP-1 siRNA and treated with LPS as indicated. (c) Levels of phospho-p38 in IEC-6 cells transiently transfected with p3XFLAG-CMV10 or pFLAG-MKP-1 and treated with LPS as indicated. (d) Levels of MKP-1 in tight Caco-2 monolayers treated with $50 \mu \mathrm{gml}^{-1} \mathrm{CpG}$ DNA applied to apical or basolateral aspect. Arrow indicates position of the MKP-1 band; other bands are due to nonspecific reactivity of the MKP-1 Ab. (e) Levels of COX-2 in IEC- 6 cells transfected as indicated and treated with LPS for $12 \mathrm{~h}$. (f) Levels of PGE metabolites (open bars) and IL-6 (filled bars) in culture supernatants of IEC-6 cells transfected and treated with LPS for $12 \mathrm{~h}$ as indicated. Brackets indicate significant differences at $P<0.05$. All results are representative of at least three independent experiments. Ab, antibody; COX-2, cyclooxygenase-2; DMSO, dimethyl sulfoxide; IL, interleukin; LPS, lipopolysaccharide; MKP, mitogenactivated protein kinase phosphatase-1; PGE, prostaglandin E; siRNA, small interfering RNA.

It has been reported that responses to TLR ligands in enterocytes may depend on apical vs. basolateral stimulation. ${ }^{13-15}$ To examine induction of MKP-1 by apical or basolateral TLR stimulation, tight Caco-2 monolayers were treated with $\mathrm{CpG}$ DNA applied to top or bottom chambers of a Transwell. Apical stimulation caused stronger MKP-1 induction than did basolateral stimulation, which is consistent with induction of MKP-1 by luminal TLR ligands (Figure 3d).

To evaluate the role of MKP- 1 in blunting inflammatory response in enterocytes, we examined effects of MKP-1 on LPSinduced expression of COX-2, the enzyme that catalyzes a ratelimiting step in the production of inflammatory prostanoids. COX-2 induction in enterocytes critically depends on $\mathrm{p} 38 .{ }^{20}$ siRNA silencing of MKP-1 potentiated induction of COX-2 by LPS. By contrast, ectopic expression of MKP-1 reduced the levels of LPS-induced COX-2 (Figure 3e). Increased expression of COX-2 was paralleled by increased levels of proinflammatory prostaglandin E (Figure 3f) Transfection with MKP-1 siRNA also increased levels of LPS-induced inflammatory cytokine IL-6 (Figure 3f). Thus, MKP-1 contributes to LPS tolerance in enterocytes by blunting TLR-mediated inflammatory responses.

Our data show that enterocytes are similar to specialized innate immune cells with regard to TLR ligand-induced expression of MKP- $1 .{ }^{26,27}$ However, in enterocytes, unlike in macrophages,
MKP-1 is not induced by TLR2 ligands. The timing of MKP-1 expression in enterocytes is consistent with the role of this phosphatase in rapid dephosphorylation of $\mathrm{p} 38$, and MKP-1 is causally linked to p38 dephosphorylation.

\section{Localization of MKP-1 in enterocytes and the intestinal epithelium}

Having established the time course of TLR ligand-induced expression of MKP-1, we set to determine, using immunofluorescence microscopy, the intracellular localization of MKP-1. Immunostaining of IEC- 6 cells with the MKP- 1 antibody $(\mathrm{Ab})$ was specific because (i) the staining was stronger in MKP1-transfected cells than in vector-transfected cells and (ii) the staining was abrogated by preincubation of the primary $\mathrm{Ab}$ with its blocking peptide (Figure 4a), or substitution of the primary $\mathrm{Ab}$ with preimmune serum (data not shown). In unstimulated cells, basally expressed MKP-1 had punctate localization in the cytosol and was largely excluded from the nuclei. Stimulation with LPS caused accumulation of nuclear MKP-1 (Figure 4b).

Localization of MKP-1 in the intestine was examined using immunofluorescent staining of paraffin sections. MKP-1 staining was specific because it was abrogated by preincubation of the primary $\mathrm{Ab}$ with its blocking peptide (Figure 4c, left). In the small intestinal epithelium of adult 
a

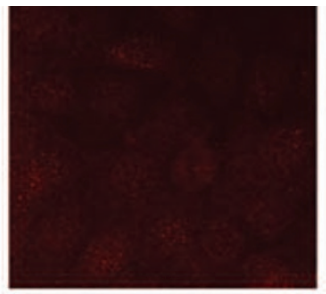

Plasmid MKP-1 peptide

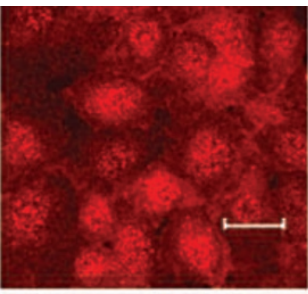

pFLAG-MKP1

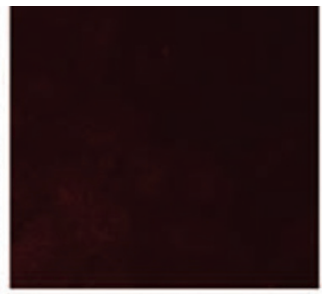

pFLAG-MKP1

$+$

b
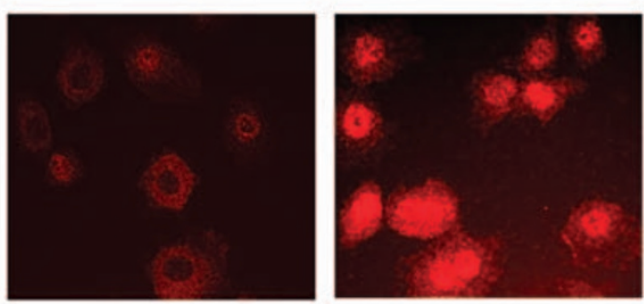

MKP-1

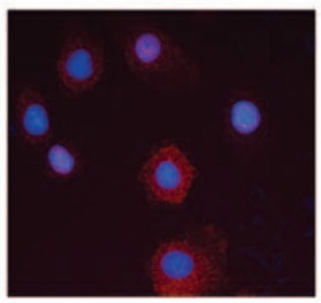

0

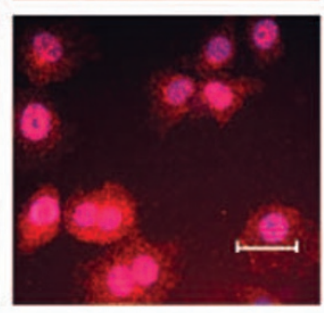

$30^{\prime}$
LPS

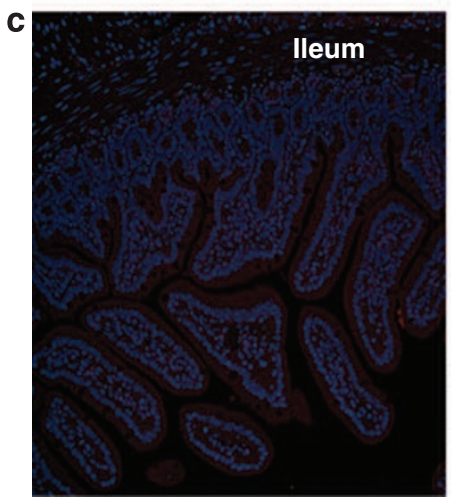

MKP-1 peptide +

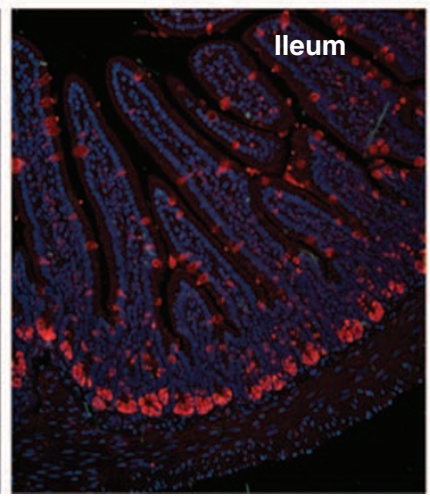

$-$

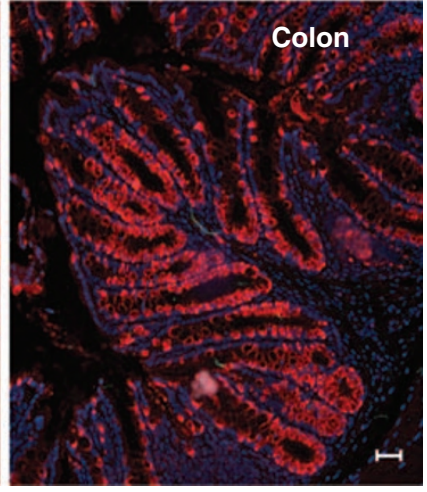

$-$

Figure 4 Localization of MKP-1 protein in IEC-6 cells and in the intestinal epithelium. (a) IEC-6 cells were transiently transfected with p3xFLAGCMV10 or pFLAG-MKP1 as indicated. Localization of MKP-1 was revealed by immunostaining with MKP-1 Ab (4 ng ml-1) preincubated with (right) or without (middle, left) its blocking peptide $\left(50 \mathrm{ng} \mathrm{ml}^{-1}\right)$ for $20 \mathrm{~min}$. (b) Localization of MKP-1 in IEC-6 cells treated with or without LPS for 30 min.

(c) Immunostaining for MKP-1 in paraffin sections of the terminal ileum and colon from conventionally housed mice. Sections were stained with MKP-1 $\mathrm{Ab}$ that was preincubated with or without its blocking peptide, as indicated. MKP-1 appears in red; DAPI-stained nuclei appear in blue. Bar $=100 \mu \mathrm{M}$. Data are representative of (panels a, b) three independent experiments, or (panel c) three different animals. Ab, antibody; DAPI, 4',6-diamidino-2phenylindole; LPS, lipopolysaccharide; MKP, mitogen-activated protein kinase phosphatase-1.

mice, MKP- 1 is expressed at high levels in the crypts and in goblet cells (Figure 4c, middle). The same localization pattern was observed in the colonic epithelium (Figure 4c, right). Previously, we have reported that intestinal crypts display benign inflammatory response, as judged by bacteriadependent activation of $\mathrm{p} 38 .{ }^{16}$ Expression of MKP- 1 in the crypts provides additional support for the role of the crypt compartment as the site of the benign homeostatic inflammatory response to luminal bacteria.

\section{LPS-induced expression of MKP-1 is mediated by NF- $\mathrm{kB}$, but} not MAPK

In macrophages and several other cell types, induction of MKP-1 by LPS is mediated by MAPK of the ERK (extracellular signalregulated kinase), ${ }^{28,29} \mathrm{JNK}$ (Jun N-terminal kinase), ${ }^{30}$ or p38 $8^{31-34}$ families. As LPS activates all these MAPKs in IEC- 6 cells, ${ }^{19}$ it was possible that these kinases mediate LPS-induced expression of MKP-1. To examine the roles of MAPK as mediators of MKP-1 induction, we used specific pharmacological inhibitors that have 
a
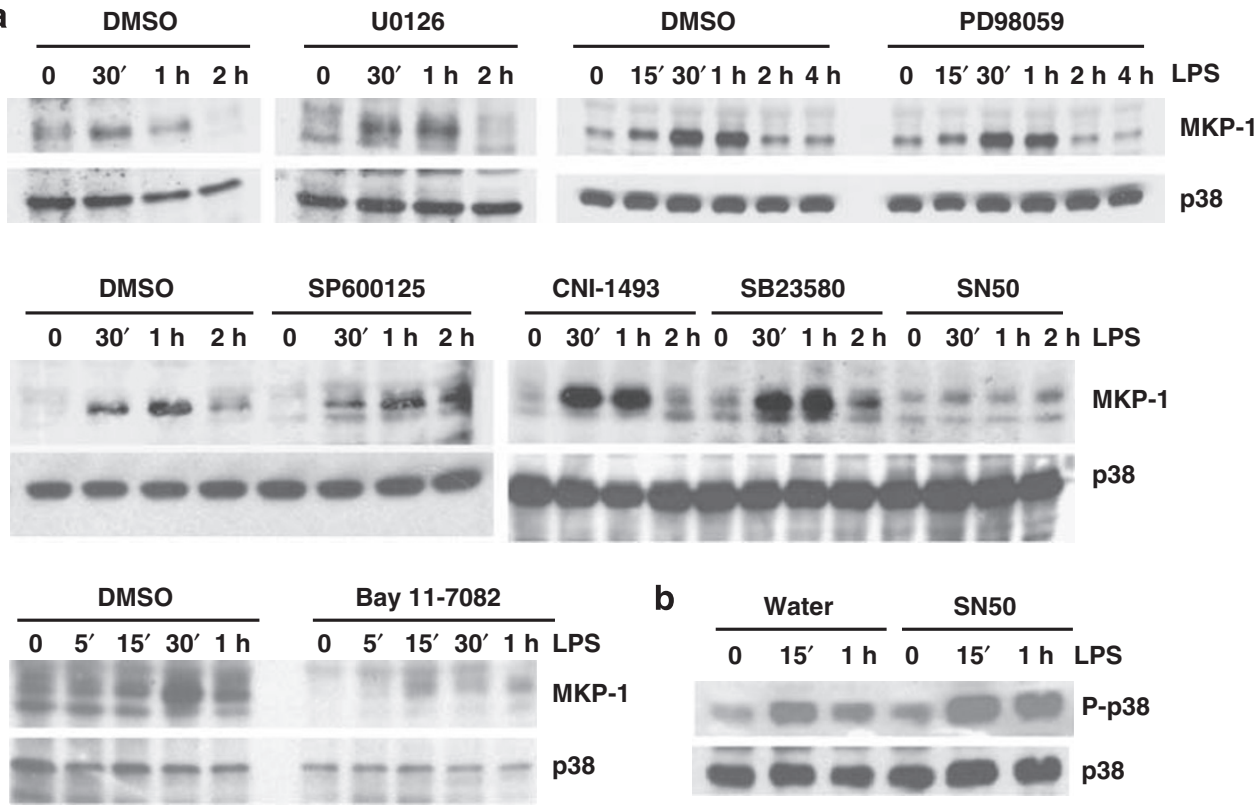

$0^{\prime} 1 \mathrm{~h}$ LPS

MKP-1

p38

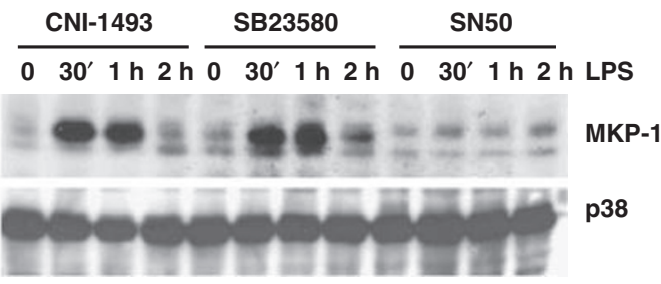

b
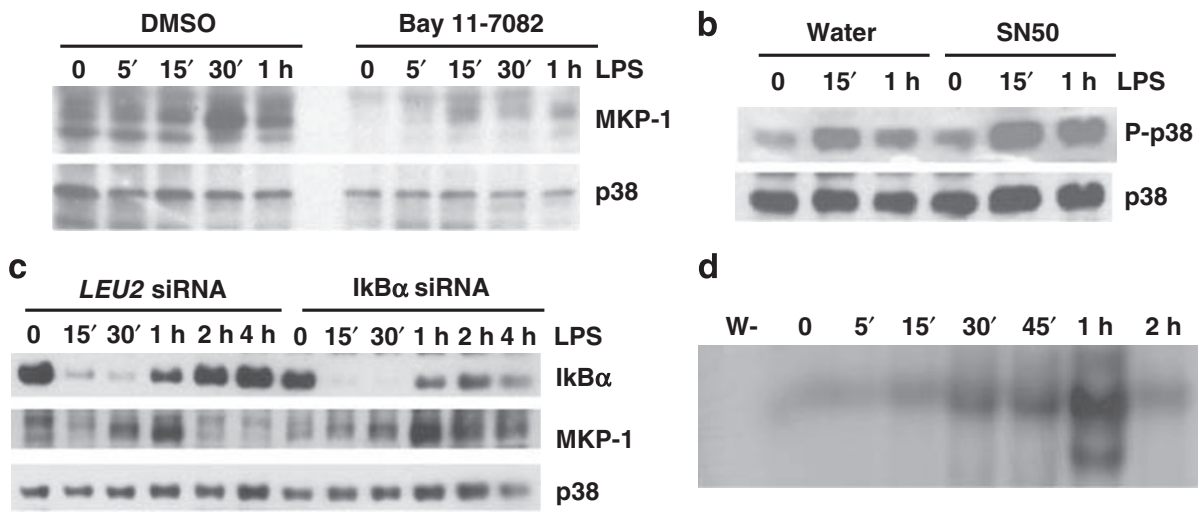

d

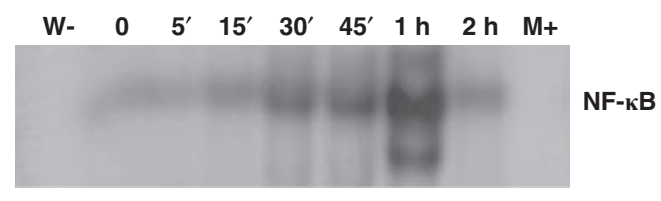

Figure 5 NF-kB, but not MAPK, mediates LPS-induced expression of MKP-1 in IEC-6 cells. (a) Time course of LPS-induced MKP-1 protein

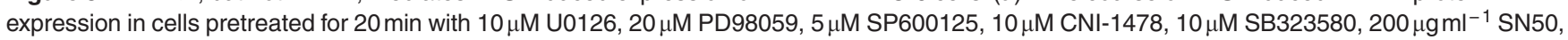
$20 \mu \mathrm{M}$ Bay11-7082, or equivalent amount of DMSO, as indicated. (b) Time course of LPS-induced phosphorylation of p38 in cells pretreated with SN50 or equivalent amount of water. (c) Levels of IkB $\alpha$ and MKP-1 proteins in cells transfected with LEU2 siRNA or IkB $\alpha$ siRNA, and treated with LPS, as

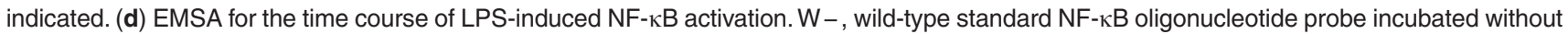
nuclear extract; $\mathrm{M}_{+}$, mutant NF-кB probe incubated with nuclear extract from cells treated with LPS for $1 \mathrm{~h}$. Data are representative of at least three independent experiments. DMSO, dimethyl sulfoxide; EMSA, electrophoretic mobility shift assay; LPS, lipopolysaccharide; MAPK, mitogen-activated protein kinase; MKP, mitogen-activated protein kinase phosphatase-1; NF- $\mathrm{KB}$, nuclear factor- $\mathrm{k}$; siRNA, small interfering RNA.

been previously validated in IEC-6 cells. ${ }^{19,20}$ U0126 and PD98059, specific inhibitors of ERK-activating MAPK kinase 1 (MKK1), SP600125, the specific inhibitor of JNK, CNI-1493 (Semapimod), the specific inhibitor of LPS-induced $\mathrm{p} 38$ phosphorylation, or SB203580, a specific inhibitor of p38, all failed to attenuate induction of MKP-1 by LPS when applied at concentrations sufficient to block their targets (Figure 5a), which rules out the significant contribution of MAPKs. In addition, MAPK-dependent induction of MKP-1 is indirectly ruled out by the fact that UVC, a strong activator of all MAPKs, failed to induce MKP-1 (Figure 2c).

Another potential mediator of LPS-induced MKP-1 expression is the proinflammatory transcription factor NF- $\mathrm{KB}$. On the one hand, NF- $\kappa B$ has been shown to mediate radiationinduced expression of MKP-1 in several cell lines, ${ }^{35}$ and on the other hand, NF- $\kappa \mathrm{B}$ is activated by LPS in enterocytes. ${ }^{36} \mathrm{SN} 50$, a cell-permeable peptide blocker of NF- $\kappa B$ translocation into the nucleus, and Bay11-7082, a specific inhibitor of the IkB kinase IKK, dramatically attenuated induction of MKP-1 by LPS (Figure 5a), suggesting a positive regulatory role for NF$\kappa B$. Treatment with SN50 prolonged LPS-induced phosphorylation of $\mathrm{p} 38$, as expected if NF- $\kappa \mathrm{B}$ mediates the expression of p38-dephosphorylating enzyme(s) (Figure 5b). Unlike the small molecule inhibitor Bay11-7082 that may potentially affect other targets at the concentration used $(20 \mu \mathrm{M})$, SN50 is a highly specific (although not very potent) NF- $\kappa B$ inhibitor. Nevertheless, we sought to corroborate pharmacological data using siRNA. Transfection of IEC- 6 cells with IkB $\alpha$ siRNA, but not with control LEU2 siRNA, attenuated resynthesis of IkB $\alpha$ following its LPS-induced degradation, and prolonged expression of MKP-1 (Figure 5c), which supports the role of NF- $\mathrm{KB}$ in LPS-induced expression of MKP-1.

Contribution of NF- $\kappa \mathrm{B}$ activation into LPS-induced expression of MKP-1 is additionally supported by the timing of both responses. In LPS-, flagellin-, CpG DNA-, or dsRNA-treated IEC- 6 cells, decreased IkB $\alpha$ and increased MKP-1 were seen at 15-30 min and 30-60 min of treatment with LPS, respectively (Figure 2a, CpG DNA and dsRNA data not shown). Considerable increase in NF- $\kappa \mathrm{B}$ binding to its cognate DNA occurred at 30-60 min of LPS treatment (Figure 5d), which agrees with published data. ${ }^{36}$ Thus, upon treatment of enterocytes with LPS, degradation of IkB $\alpha$ precedes the expression of MKP-1, whereas increase in NF- $\kappa \mathrm{B}$ DNA-binding coincides with it, consistent with NF- $\kappa B$ mediating MKP-1 induction by LPS. 
MKP-1 promoters contain NF- $\kappa \mathrm{B}-$ binding sites

If $\mathrm{NF}-\kappa \mathrm{B}$ directly activates the transcription of $\mathrm{MKP}-1$, the MKP-1 promoter should contain NF- $\kappa \mathrm{B}$-binding sites. The human MKP-1 promoter contains an NF- $\kappa \mathrm{B}$ site that is important for transcriptional activation by radiation. ${ }^{35} \mathrm{MKP}-1$ promoters of human, orangutan, chimpanzee, macaque, horse, cow, dog, and rat all contain exact matches to the NF- $\kappa \mathrm{B}$ consensus site GGGRNNYYCC within the $2.2 \mathrm{~kb}$ upstream region (Table 1 ). Interestingly, putative $\mathrm{NF}-\kappa \mathrm{B}$ sites in MKP-1 promoters of these species are conserved beyond the match to the consensus: they have the corebinding element GGGGTCTYCC immediately followed by the motif CARNNG, whereas other sequences surrounding

Table 1 Putative NF- $\kappa$ B binding sites in mammalian MKP-1 promoters

\begin{tabular}{|c|c|c|c|}
\hline Species & Sequence $^{a}$ & Location $^{b}$ & Match $^{\mathrm{C}}$ \\
\hline \multirow{3}{*}{$\begin{array}{l}\text { Human, } \\
\text { Chimpanzee }\end{array}$} & GGGGTCTTCCcaagtg & -1439 & Exact \\
\hline & GGGGAACCTCagtttc & -778 & -1 \\
\hline & AGGAAGCCCCtttcgg & -705 & -1 \\
\hline \multirow[t]{2}{*}{ Orangutan } & GGGGTCTTCCcaagcg & -1438 & Exact \\
\hline & AGGAAGCCCCtttcgg & -704 & -1 \\
\hline \multirow[t]{3}{*}{ Macaque } & GGGGTCTTCCcaagcg & -1447 & Exact \\
\hline & GGGGAACCTCagtttc & -773 & -1 \\
\hline & AGGAAGCCCCtttcgg & -701 & -1 \\
\hline \multirow[t]{2}{*}{ Cow } & GGGGTCTCCCcaaacc & -1580 & Exact \\
\hline & AGAAAATCCCcaggag & -1272 & -1 \\
\hline \multirow[t]{2}{*}{ Horse } & GGGGTCTTCCcaaacg & -2177 & Exact \\
\hline & GGAAAGCTCCcaatcc & -2016 & -1 \\
\hline \multirow[t]{2}{*}{ Dog } & GGAAAACCCCacagag & -1999 & Exact \\
\hline & GGGGTCTTCCcaaacg & -1319 & Exact \\
\hline \multirow[t]{3}{*}{ Mouse } & GGGAAACTCCtcactg & -2520 & Exact \\
\hline & AGGGGACCCCagaact & -1775 & -1 \\
\hline & GGGATGTTTCctcttc & -1083 & -1 \\
\hline \multirow[t]{2}{*}{ Rat } & GGGGTCTTCCcaggtg & -1164 & Exact \\
\hline & GAGACACTCCtttgtc & -709 & -1 \\
\hline \multirow[t]{2}{*}{ Rabbit } & GGGGAGCCTCtgctta & -2294 & -1 \\
\hline & GGGACCTTTCtgagct & -2160 & -1 \\
\hline
\end{tabular}

MKP-1, mitogen-activated protein kinase phosphotase-1; NF- $\kappa B$, nuclear factor $-\kappa B$. ${ }^{a}$ Core decanucleotide NF-кB binding sequence capitalized.

bPosition relative to MKP-1 translational start.

${ }^{c}-1$, one nucleotide conservative deviation $(R \rightarrow R$ or $Y \rightarrow Y)$ from NF- $\kappa B$ consensus sequence GGGRNNYYCC or its reverse complement GGRRNNYCCC. the NF- $\kappa \mathrm{B}$ consensus sites are not conserved, except for primates. The mouse MKP-1 promoter has a perfect match (GGGAAGCCCC) to the NF- $\kappa \mathrm{B}$ consensus sequence at $-2,520 \mathrm{bp}$, whereas the rabbit MKP-1 promoter has only close matches (GGGGAGCCTC and GGGACCTTTC) at $-2,294$ and $-2,160$, respectively. In addition to the sites that exactly match the NF- $\kappa \mathrm{B}$ consensus sequence, most mammalian MKP-1 promoters examined contain closely matching sequences. For example, the rat MKP-1 promoter has a sequence GAGACACTCC (site 2) at - 709 (Table 1). To test whether putative NF- $\kappa \mathrm{B}$ sites of the rat MKP-1 promoter bind NF- $\kappa \mathrm{B}$, we performed electrophoretic mobility shift assay (EMSA) with oligonucleotide probes corresponding to these sites. Mutant probes with $\mathrm{G} \rightarrow \mathrm{C}$ substitutions at position +3 of the consensus sequence, and standard NF$\kappa \mathrm{B}$ probe were included as controls. Probes corresponding to wild-type, but not to mutant, sequences of sites 1 and 2 of the MKP-1 promoter bound NF- $\kappa \mathrm{B}$ with the same efficiency as the standard NF- $\kappa \mathrm{B}$ probe (Figure 6a). Binding in the presence of Abs against p65 or p50 subunits of $N F-\kappa B$ caused supershifting of the NF- $\kappa \mathrm{B}$ bands, indicating specific association of NF- $\kappa \mathrm{B}$ with MKP-1 probes. Moreover, because supershifting was nearly quantitative (Figure 6a), NF- $\kappa \mathrm{B}$

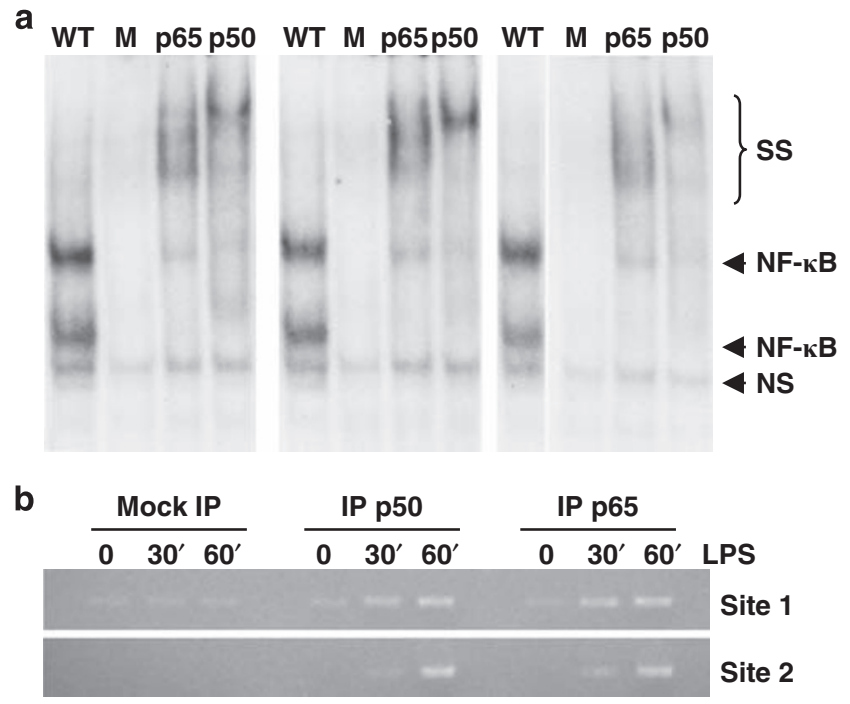

Figure 6 NF- $\kappa B$ binds its cognate sites in the MKP-1 promoter. (a) EMSA for NF-kB-binding to sites 1 and 2 of the rat MKP-1 promoter, compared with standard NF-kB probe. Wild-type (WT) and mutant (M) ${ }^{32} \mathrm{P}$-labeled oligonucleotide probes corresponding to NF-kB-binding sites were incubated with nuclear extracts from IEC-6 cells treated with LPS for $1 \mathrm{~h}$. Abs against $\mathrm{p} 65$ and $\mathrm{p} 50$ subunits of NF- $\mathrm{kB}$ were added to binding reactions as indicated. Positions of nonspecific (NS), NF-kB,

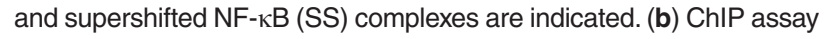
for LPS-induced binding of NF-KB to the MKP-1 promoter. Chromatin fragments from IEC-6 cells treated with LPS for indicated time were mock immunoprecipitated with preimmune serum or immunoprecipitated with anti-p65 or anti-p50 Abs. Immunoprecipitated DNA was amplified using PCR with primers flanking sites 1 or 2 , and PCR products were resolved on agarose gel. Data are representative of at least three independent experiments. Ab, antibody; ChIP, chromatin immunoprecipitatioin; EMSA, electrophoretic mobility shift assay; LPS, lipopolysaccharide; MKP, mitogen-activated protein kinase phosphatase-1; NF- $\mathrm{KB}$, nuclear factor- $\mathrm{kB}$. 
appears to bind the wild-type MKP-1 probes as a p50-p65 heterodimer. Thus, NF- $\kappa \mathrm{B}$ sites of the rat MKP- 1 promoter bind $\mathrm{p} 50 / \mathrm{p} 65 \mathrm{NF}-\mathrm{\kappa B}$ heterodimers in vitro.

\section{NF- $\kappa B$ binds the MKP-1 promoter in LPS-treated IEC- 6 cells}

We next tested NF- $\kappa B$ binding to the MKP-1 promoter in IEC- 6 cells using chromatin immunoprecipitatioin. IEC- 6 cells were treated with LPS and fixed with formaldehyde to stabilize DNAprotein complexes. After sharing DNA by sonication, chromatin fragments were immunoprecipitated with Abs against p50 or p65 NF- $\mathrm{KB}$ subunits. Coimmunoprecipitated DNA was used as template for PCR with pairs of primers flanking NF- $\kappa B$ sites in the MKP-1 promoter. Figure $\mathbf{6 b}$ and Supplementary Figure S3 online show that treatment with LPS significantly increased amounts of the MKP-1 promoter DNA coimmunoprecipitated by anti-p50 or anti-p65 Abs, but not by preimmune serum, indicating LPS-induced binding of p50-p65 complexes to the NF- $\mathrm{kB}$ sites of the MKP-1 promoter.

\section{Activation of the MKP-1 promoter by LPS depends on its NF- $\kappa$ B sites}

The presence of functional NF- $\kappa \mathrm{B}$ sites in the MKP-1 promoter, LPS-induced binding of NF- $\kappa B$ to these sites, blockade of LPS-induced expression of MKP- 1 by NF- $\kappa \mathrm{B}$ inhibitors, and prolongation of LPS-induced MKP- 1 expression by $\mathrm{IkB} \alpha$ siRNA suggested that the MKP-1 promoter is directly activated by NF- $\kappa \mathrm{B}$. To examine the roles of NF- $\kappa \mathrm{B}$ sites in LPS-induced transcription, we used the MKP-1-luciferase (luc) transcriptional reporter. A 2,058 bp genomic fragment from the rat MKP-1 promoter $(-2,087$ to -30$)$ was inserted in direct orientation in front of the luc coding sequence in pGL3, placing the luc gene under control of the MKP-1 promoter. Single loss-of-function $\mathrm{G} \rightarrow \mathrm{C}$ mutations in each of the two NF- $\kappa \mathrm{B}$-binding sites, as well as double mutation, were constructed using site-directed mutagenesis. Wild-type and mutant reporter plasmids were transiently cotransfected into IEC- 6 cells with a Renilla luciferase plasmid, the latter as control for transfection efficiency. Firefly and Renilla luciferases use different chemical reactions, allowing sequential measurement of their activities in the same sample. Transfectants were stimulated with or without LPS. Firefly luciferase activities were normalized to Renilla luciferase activities. Cells transfected with promoterless pGL3 plasmid displayed luc activity indistinguishable from background (data not shown). The MKP-1 promoter stimulated basal expression of $l u c$ at $\sim 1 / 4$ of the LPS-induced level (Figure 7). This is in agreement with published observations of relatively high constitutive activity of MKP-1 promoter fragments. ${ }^{37,38}$ Mutational inactivation of either NF- $\kappa \mathrm{B}$ site 1 or site 2 decreased LPS-induced luc activity, each approximately twofold, whereas inactivation of both sites completely abolished LPS-induced expression. $\mathrm{NF}-\kappa \mathrm{B}$ mutations did not significantly alter the basal expression of MKP-1-luc (Figure 7). These data show that in IEC-6 cells, LPS-induced transcription from the MKP-1 promoter depends on its two NF- $\kappa B$ sites, and that each site additively contributes to the overall induction.

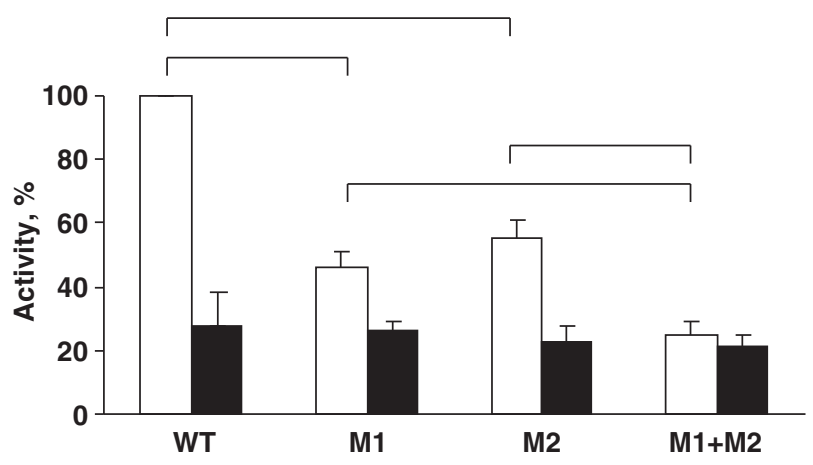

Figure $7 \quad$ NF-kB-binding sites cooperatively regulate LPS-induced transcription from the MKP-1 promoter. IEC- 6 cells transiently cotransfected with Renilla luciferase construct and wild-type (WT), or site 1 mutant (M1), or site 2 mutant (M2), or double mutant (M1 + M2) pGL3MKP1 constructs were treated with (open bars) or without (filled bars) LPS for $1 \mathrm{~h}$. Firefly luciferase activity in each sample was normalized to Renilla luciferase activity and expressed as a fraction of the activity of LPSinduced WT reporter lysates. Brackets indicate significant differences

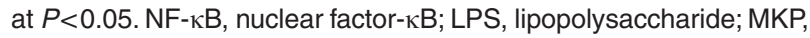
mitogen-activated protein kinase phosphatase-1.

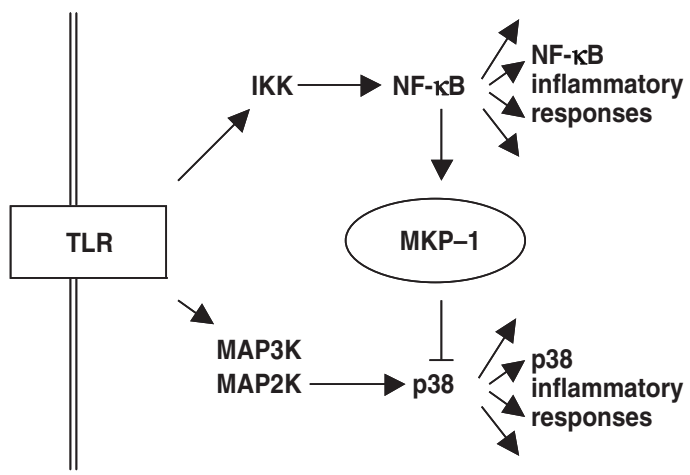

Figure 8 NF-kB downregulates p38 by induction of MKP-1 in TLR ligand-stimulated enterocytes. TLRs activate NF- $\mathrm{KB}$ and p38 through distinct signaling pathways that involve IKK and upstream MAPK kinases MAP3K and MAP2K, respectively. NF- $\kappa B$ promotes transcriptional expression of MKP-1, which in turn deactivates $\mathrm{p} 38$. NF- $\mathrm{kB}$ and $\mathrm{p38}$ regulate distinct subsets of inflammatory responses. MAPK, mitogenactivated protein kinase; MKP, mitogen-activated protein kinase phosphatase-1; NF-kB, nuclear factor- $\mathrm{KB}$; TLR, Toll-like receptor.

\section{DISCUSSION}

Our findings identify NF- $\kappa B$-mediated induction of the dual specificity phosphatase MKP-1 as a mechanism that rapidly downregulates $\mathrm{p} 38$-mediated innate immune signaling in enterocytes. In this mechanism, activation of TLR3, TLR4, TLR5, or TLR9 by their ligands leads to degradation of IkB $\alpha$, binding of $\mathrm{NF}-\kappa \mathrm{B}$ to the MKP-1 promoter, and transcriptional activation of the MKP-1 gene. Exposure of enterocytes to TLR3, TLR4, TLR5, or TLR9 ligands also activates $\mathrm{p} 38$; however, the ensuing induction of MKP-1 rapidly reverses this activation. As a result, p38 activation is transient (Figure 8).

The role of NF- $\kappa \mathrm{B}$-mediated expression of MKP-1 in deactivation of $\mathrm{p} 38$ is supported by the following observations. First, stimuli that cause sustained activation of p38, such as TLR2 ligands or UVC, do not activate NF- $\kappa B$ and do not induce MKP-1. 
Second, inhibition of NF- $\mathrm{KB}$ signaling, as well as blockade of new protein synthesis, abrogate LPS-induced expression of MKP-1 and prolong activation of $\mathrm{p} 38$. By contrast, siRNA knockdown of IkB $\alpha$ prolongs MKP- 1 expression. Third, NF- $\kappa B$ binds MKP- 1 promoter in vitro and in vivo in a LPS-inducible manner. Fourth, LPS induces expression of MKP-1 transcriptional reporter in a manner dependent on its NF- $\kappa B$ sites. Finally, in LPS-treated cells, MKP-1 protein expression temporally coincides with NF- $\kappa B$ activation.

Our results support the role of MKP-1 as an important negative regulator of innate immune responses in enterocytes. Several groups reported that $m k_{p} 1^{-1}$ mice mount exaggerated inflammatory responses, produce abnormally high levels of inflammatory factors, and display hypersensitivity to multiple organ failure upon challenge with LPS or bacteria. ${ }^{27,39-41}$ TLR ligand-stimulated $m k p 1^{-1-}$ macrophages express abnormally high levels of inflammatory cytokines due to their inability to efficiently downregulate p38-mediated inflammatory signaling. ${ }^{40,42,43} \mathrm{MKP}-1$ has been also shown to downregulate inflammatory signaling in cell types other than macrophages. ${ }^{44}$ In macrophages, LPS and peptydoglycan transiently induce MKP-1, with the time course of this induction consistent with MKP-1-dependent dephosphorylation of p38. ${ }^{26,39}$ However, our data show important cell-type differences in the mechanisms of MKP-1 induction. In macrophages, MKP- 1 is induced by LPS through p38 and ERK, ${ }^{28,32}$ but in enterocytes, these MAPK are dispensable, whereas $\mathrm{NF}-\kappa \mathrm{B}$ is essential. MKP-1 is induced by peptydoglycan in macrophages, ${ }^{27}$ but not in enterocytes.

Failure of TLR2 ligands to induce IkB $\alpha$ degradation and MKP-1 expression in enterocytes suggests that in these cells, TLR2 uses some signaling mechanisms that are not shared with other TLRs. Our observation of the unique properties of TLR2 signaling in enterocytes support findings of Cario et al. ${ }^{45}$ who reported a lack of considerable NF- $\mathrm{\kappa B}$ activation by $\mathrm{Pam}_{3} \mathrm{CSK}_{4}$ or peptydoglycan in enterocytes. According to their study, TLR2 ligands fail to robustly activate NF- $\mathrm{KB}$ because, unlike the TLR4 ligand LPS, they activate the phosphoinositide 3-kinase pathway, which downregulates NF- $\mathrm{kB}$. TLR2-mediated responses specifically promote barrier integrity and protect enterocytes from apoptosis. ${ }^{45}$ As the vast majority of normal gut microbiota express TLR2 ligands, it is likely that relatively weak, but sustained TLR2-dependent activation of $\mathrm{p} 38$ in enterocytes has a role in benign homeostatic response to these beneficial commensals.

TLR ligand-induced expression of MKP-1 may contribute to fine-tuning the balance between proinflammatory and antiinflammatory responses, which is required for the establishment and maintenance of a mutualistic relationship between the luminal microbiota and the intestinal epithelium. In enterocytes, the proinflammatory responses, including production of inflammatory prostanoids and cytokines such as IL- 8 are mediated by p38. ${ }^{20-22,46}$ By contrast, most protective, homeostatic, and restitution responses, including production of antibacterial peptides, antiapoptotic proteins, or restitution-promoting cytokines are

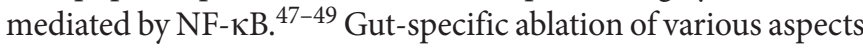

of NF- $\kappa \mathrm{B}$ signaling renders the epithelium hypersensitive to the induction of inflammation by commensal bacteria, ${ }^{49-51}$ presumably due to the failure to express NF- $\mathrm{KB}$-dependent protective factors, one of which is MKP-1.

In the intestine, levels of MKP-1 are high in crypt enterocytes, but not in the majority of villus enterocytes. This pattern may be associated with macroscopic compartmentalization of TLR signaling in the epithelium. We have shown that in the mouse small intestine, bacteria-dependent activation of p38 is limited to crypts, whereas the villus epithelium becomes refractory to LPS because of induction of the anti-inflammatory ubiquitin-editing enzyme A20. ${ }^{16}$ Suppression of TLR signaling at the luminal interface of the villi may also involve downregulation of TLR and induction of Tollip. ${ }^{7,11}$ It is possible that deep in the crypts, where exposure to intestinal bacteria is limited, emerging enterocyte precursors are sensitive to TLR ligands. As these cells divide, differentiate, and migrate toward crypt openings, their exposure to TLR ligands activates inflammatory signaling. However, this signaling is short lived in each cell because engagement of the inhibitory mechanisms, one of which is NF- $\mathrm{KB}$-mediated expression of MKP-1, rapidly shuts it down. It is noteworthy that the inhibitory effect of MKP-1 on p38mediated TLR signaling in enterocytes is rapid, but transient. Therefore, MKP- 1 is likely to act as an early, reversible inhibitor that contributes to rapid establishment of unresponsiveness to commensal bacteria in the emerging enterocytes. Maintenance of the tolerant state is then taken over by longer-lasting negative regulators, such as A20, Tollip, or downregulation of TLR. The significance of high-level expression of MKP-1 in goblet cells remains unknown. It is possible that p38 activation is incompatible with the secretory function or maintenance of goblet cells; therefore, MKP-1 may be expressed as a part of goblet celldifferentiation program.

Inhibition of TLR ligand-induced activation of p38 by $\mathrm{NF}-\mathrm{\kappa B}$ in enterocytes argues that $\mathrm{p} 38$ and NF- $\mathrm{\kappa B}$ regulate distinct innate immune functions. Indeed, in IEC- 6 cells and in the neonatal intestinal epithelium, p38, but not NF- $\mathrm{kB}$ is required for LPS-induced expression of COX-2, the key enzyme in the biosynthesis of proinflammatory prostanoids, ${ }^{19,20}$ whereas $\mathrm{NF}-\kappa \mathrm{B}$, but not $\mathrm{p} 38$ is required for IL- $1 \beta$-induced expression of inducible nitric oxide synthase, the enzyme that catalyzes production of inflammatory nitric oxide. Moreover, pharmacological inhibition of $\mathrm{p} 38$ augments IL- $1 \beta$-induced expression of inducible nitric oxide synthase, whereas pharmacological inhibition of NF- $\kappa \mathrm{B}$ augments expression of COX-2 (Lugo B., Wang J., Grishin A. V., and Ford H. R., unpublished data). Thus, MKP-1 may have a role as a molecular switch that coordinates signaling through NF- $\mathrm{KB}$ and $\mathrm{p} 38$ branches of the inflammatory cascade in the intestine.

\section{METHODS}

Reagents. Commercial reagents were obtained from the following suppliers: MKP-1 Ab M18 and its blocking peptide, NF- $\kappa \mathrm{B}$ p50 and $\mathrm{p} 65 \mathrm{Abs}$, standard wild-type and mutant NF- $\kappa \mathrm{B}$ EMSA probes (Santa Cruz Biotechnology, Santa Cruz, CA); p38, phospho-p38, $\mathrm{IkB} \alpha$ Abs (Cell Signaling Technology, Danvers, MA); Bay11-7082, SB203580, SP600125, U0126, PD98059, LPS from Escherichia coli 
0127:B8, lipoteichoic acid, peptidoglycan, sanguinarine (SigmaAldrich, St Louis, MO); SN50 (Alexis Biochemicals, Plymouth Meeting, PA); $\mathrm{Pam}_{3} \mathrm{CSK}_{4}$, (EMC Microcollections, Tuebingen, Germany); purified Salmonella typhimurium flagellin (Invivogen, San Diego, CA); poly (I:C) (Pharmacia, Uppsala, Sweden); prostaglandin E metabolite EIA kit (Cayman Chemicals, Ann Arbor, MI); rat IL-6 EIA kit (Becton Dickinson, San Jose, CA). LPS was additionally purified by DNAse I/proteinase K digestion, phenol extraction, and ethanol precipitation. LPS-induced phosphorylation of $\mathrm{p} 38$ and expression of MKP-1 in IEC-6 cells were completely abrogated by preincubation of LPS with $20 \mu \mathrm{g} \mathrm{ml}^{-1}$ polymyxin B or adsorption on polymyxin B-agarose beads (Sigma-Aldrich), which rules out contamination with other TLR ligands. Synthetic oligonucleotide TCGTCGTTTCGTCGTTTTGTCGTT was used as unmethylated CpG DNA.

siRNAs. A 626-bp sequence at the $5^{\prime}$ end of I $\kappa \mathrm{B} \alpha \mathrm{cDNA}$ was amplified from IEC- 6 total RNA using reverse transcriptase-PCR with primers GGTAATACGACTCACTATAGGAACAGTCTGAACTCGCCACCC AA and GGTAATACGACTCACTATAGGTAGACACGTGTGGCCG TTGTAGTT. MKP-1 coding sequence was amplified with primers $G$ GTAATACGACTCACTATAGGGCTCCTTCTTCGCCTTCAACGC and GGTAATACGACTCACTATAGGCGGAGAGGTTGTGATGGGG CTTTG. The resulting DNA fragments were used as templates in T7 RNA polymerase reactions to synthesize dsRNAs, which were then cut into 21-bp duplexes using the Short-Cut RNAse (New England Biolabs, Ipswich, MA). Control LEU2 siRNA was prepared similarly using yeast DNA template with GGGTAATACGACTCACTATAGCACGTTGTCA AGAAATC and GGGTAATACGACTCACTATAGAACTTCTTCGGC GACAGCATCACC primers.

MKP-1 expression plasmid. Rat MKP-1 open reading frame was amplified from RNA of LPS-treated IEC-6 cells using reverse transcriptase-PCR with primers GGGAATTCAGTGATGGAGGTGGGCATCCTGGAC and GGGATCCCTTCAGCAGCTCGGAGAGGTTG. Reverse transcriptase-PCR product was cut with EcoRI and $B a m H I$, and inserted into EcoRI-BamHI-cut p3XFLAG-CMV10 (Sigma-Aldrich) to obtain pFLAG-MKP1. MKP-1 coding region and junctions were sequenced to verify the absence of spurious mutations.

Cell culture and transfections. IEC-6, IEC-18, SW480, and Caco-2 cell lines were purchased from American Type Culture Collection (Manassas, VA) and cultured as recommended by the supplier. RIE-1 cells were provided by $\mathrm{Dr}$ Hua $\mathrm{Xu}$, University of Arizona. Cells were used at passages 19-30. Tight Caco-2 monolayers were established by seeding cells in $24-\mathrm{mm}$ Transwells $(0.4 \mu \mathrm{m}$ pore size, Costar, Cambridge, MA) and exposing the monolayers to BioCoat Enterocyte Differentiation Medium (Becton Dickinson, Bedford, MA) for 3 days. Transepithelial electric resistance of the monolayers, as measured with EVOM (World Precision Instruments, Sarasota, FL), was at least $300 \mathrm{Ohm} \mathrm{cm}^{2}$. For transient transfection, IEC-6 cells were grown overnight to $90-95 \%$ confluence, gently trypsinized, diluted in RPMI $+10 \%$ fetal bovine serum, and collected by centrifugation at 200 r.p.m. After removal of residual medium, $3 \times 10^{7}$ cells were gently mixed with $10 \mu \mathrm{g}$ plasmid DNA in $90 \mu \mathrm{l}$ of Nucleofector Solution V (Lonza, Basel, Switzerland), and immediately pulsed using the T-030 program of Nucleofector (Lonza). Cells were allowed to recover in RPMI $+10 \%$ fetal bovine serum for $10 \mathrm{~min}$ at $37^{\circ} \mathrm{C}$ and transferred into a $100 \mathrm{~mm}$ Petri plate containing $10 \mathrm{ml}$ of IEC6 medium. Overall, $40-80 \%$ of surviving cells were transfected, as judged by the percentage of green fluorescent cells following control transfection with pMAX-GFP (green fluorescent protein) (Lonza). GFP expression was detectable 1-7 days after transfection. Cells were transfected with siRNAs using Lipofectamine 2000 as recommended by the manufacturer (Invitrogen, Carlsbad, CA) using $4 \mu \mathrm{g}$ siRNA, $50 \mu \mathrm{l}$ Lipofectamine, and $2 \mathrm{ml}$ Dulbecco's modified Eagle's medium per $60 \mathrm{~mm}$ Petri plate.
Western blots. Cells were lysed with RIPA buffer (1\% NP-40, 0.5\% deoxycholate, $0.1 \%$ SDS, $20 \mathrm{mM}$ Tris $\mathrm{pH} 8.0,100 \mathrm{mM} \mathrm{NaCl}, 20 \mathrm{mM}$ $\mathrm{NaF}, 1 \mathrm{mM}$ sodium pyrophosphate, $0.1 \mathrm{mM}$ phenylarsine oxide, $0.1 \mathrm{mM}$ sodium orthovanadate, $0.1 \mathrm{mM}$ phenylmethylsulfonyl fluoride, $0.1 \mathrm{mM}$ benzamidine, $1 \mu \mathrm{g} \mathrm{ml}^{-1}$ leupeptin, $1 \mu \mathrm{g} \mathrm{ml}^{-1}$ pepstatin). Lysates $(50 \mu \mathrm{g}$ protein per lane) were separated by SDS-PAGE, and proteins were electrotransferred from gel onto nitrocellulose membrane. Membranes were blocked in Tris-buffered saline, $0.1 \%$ Tween $20,2 \%$ fish gelatin, and incubated with primary and secondary horseradish peroxidase-conjugated Abs. Protein bands were visualized using West Pico chemiluminescence detection system (Pierce, Rockford, IL).

Immunofluorescence microscopy. Cultured enterocytes were fixed in cold acetone and air dried. Intestinal sections were deparaffinized, rehydrated by sequential incubation in $100 \%$ ethanol, $70 \%$ ethanol, and water at room temperature followed by $10 \mathrm{~min}$ boiling in $10 \mathrm{mM}$ sodium citrate pH 7.0. Samples were blocked in Tris-buffered saline Tween- $20+2 \%$ normal donkey serum, and incubated with primary and fluorescent dye-conjugated secondary Abs as recommended by the manufacturers. Samples were mounted with DAPI (4',6-diamidino-2-phenylindole). Images were acquired using BX51 microscope equipped with color camera and Picture Frame software (Olympus, Center Valley, PA). For comparisons, samples were processed in parallel on the same slide, and images were acquired and adjusted identically.

EMSA. Oligonucleotide probes encompassing NF- $\kappa \mathrm{B}$ consensus sites of the rat MKP-1 promoter (site 1: atcgttGGGGTCTTCCcaggt; site 2: ctaactGGaGACACTCCtttgt; matches to the consensus NF$\kappa \mathrm{B}$-binding sequence GGGRNNYYCC capitalized) were prepared by annealing complementary oligonucleotides and labeling gelpurified duplexes with $\gamma-\left[{ }^{32} \mathrm{P}\right] \mathrm{ATP}$ and T4 polynucleotide kinase. Mutant probes were generated by introducing $\mathrm{G} \rightarrow \mathrm{C}$ transversions at position 3 of the NF- $\kappa \mathrm{B}$ consensus sequence. Nuclear extracts for EMSA were prepared by extracting nuclei with high-salt buffer (20 mM HEPES pH 7.9, $1.5 \mathrm{mM} \mathrm{MgCl}_{2}, 300 \mathrm{mM} \mathrm{KCl}, 20 \%$ glycerol). $15 \mu \mathrm{l}$ binding reactions $(20,000$ c.p.m. probe, $10 \mu \mathrm{g}$ nuclear extract protein, $1 \mu \mathrm{g}$ poly (dI:dC), $1 \mu \mathrm{g}$ bovine serum albumin, $20 \mathrm{mM}$ HEPES pH 7.9, $100 \mathrm{mM} \mathrm{KCl,} \mathrm{20 \%} \mathrm{glycerol,} \mathrm{with} \mathrm{or} \mathrm{without} 2 \mu \mathrm{g}$ $\mathrm{NF}-\kappa \mathrm{B}$ Abs) were incubated $1 \mathrm{~h}$ at room temperature and resolved on nondenaturing gels ( $6 \%$ acrylamide, $0.24 \%$ Bis, $25 \mathrm{mM}$ Tris, $200 \mathrm{mM}$ glycine, $5 \%$ glycerol). Gels were soaked in $10 \%$ methanol, $10 \%$ acetic acid, dried, and autoradiographed.

Chromatin immunoprecipitatioin. Chromatin immunoprecipitatioin kit (Upstate Biotechnology, Billerica, MA) was used as directed by the manufacturer. Briefly, cells were fixed with formaldehyde and sonicated to average DNA size of $500 \mathrm{bp}$. Cell lysates were incubated with NF- $\kappa \mathrm{B}$ p65 Abs, p50 Abs, or preimmune rabbit serum, and immunoprecipitates were collected on Protein A agarose. Upon extensive washing, DNA was purified from the immunoprecipitates by Proteinase K digestion, phenol/chloroform extraction, and ethanol precipitation, and used as template for PCR with NF- $\kappa$ B site flanking primers (AAACCGCAGA ATGTTCCTGACTCG and AGAGAGGTCTTGCTGTTTAGCCCT for site 1, AATTTGCAACCCTCCTCCCTTTGC and ACTCCTGGGATCACGGTCTCAGTT for site 2,32 cycles of $95^{\circ} 5 \mathrm{~s}, 55^{\circ}$ $5 \mathrm{~s}, 72^{\circ} 30 \mathrm{~s}$ ). PCR products of 328 and $301 \mathrm{bp}$ were analyzed by agarose gel electrophoresis. Levels of MKP-1 promoter DNA were determined using real-time PCR with the same pairs of primers and SYBR Green PCR Master Mix (Applied Biosystems, Foster City, CA) as recommended by the manufacturer.

Luciferase reporter assay. MKP-1 transcriptional reporter (pGL3MKP1) was constructed by amplifying 2,058 bp of the MKP-1 upstream sequence from rat genomic DNA with primers GGCTCGAGCAGGA TTCTCTAAGGTTC and CGGAAGCTTCTGCAGCTCTCC AGAA, cutting the PCR product with XhoI and HindIII, and ligating it into XhoIHindIII-cut pGL3 (Promega, Madison, WI). The absence of spurious 
mutations in the MKP-1 promoter sequence was verified by sequencing. NF- $\kappa B$-binding site mutations were introduced using the Quick Change Multi mutagenesis kit (Stratagene, La Jolla, CA). Reporter plasmids were transiently cotransfected with the Renilla luciferase plasmid (Promega) into IEC-6 cells. After stimulation, firefly and Renilla luciferase activities were determined using the Dual Luciferase kit (Promega). Luminescence was measured using tritium channel of a scintillation counter. Samples were counted for $1 \mathrm{~min}$, with time between addition of cell lysate to reaction and start of counting standardized to $20 \mathrm{~s}$.

Sequence analysis. Sequences of 3,000 bp mammalian genomic regions upstream of MKP-1 translation start were retrieved from the ENSEMBL genome sequence database. Exact matches to the NF- $\kappa \mathrm{B}$ consensus-binding site (GGGRNNYYCC) or its reverse complement (GGRRNNYCCC), as well as sequences with a conservative one-nucleotide deviation $(R \rightarrow R$ or $\mathrm{Y} \rightarrow \mathrm{Y}$ ) were located using text search.

Statistical analysis. Quantitative data are average \pm s.e. of three independent experiments, each performed in triplicate. Parametric data were compared using Student's $t$-test, and nonparametric data using MannWhitney test, with significance at $P<0.05$.

SUPPLEMENTARY MATERIAL is linked to the online version of the paper at http://www.nature.com/mi

\section{ACKNOWLEDGMENTS}

We thank Patricia Boyle-Lockerbie and Kerstin Goth for skilled technical assistance, and Hua Xu for the gift of RIE-1 cells. This study was supported by NIH Al083612 (A.V.G), Al014032 (H.R.F), and Al 049473 (H.R.F).

\section{DISCLOSURE}

The authors declared no conflict of interest.

2010 Society for Mucosal Immunology

\section{REFERENCES}

1. Gribar, S.C., Richardson, W.M., Sodhi, C.P. \& Hackam, D.J. No longer an innocent bystander: epithelial Toll-like receptor signaling in the development of mucosal inflammation. Mol. Med. 14, 645-659 (2008).

2. Sanderson, I.R. \& Walker, W.A. TLRs in the gut I. The role of TLRs/Nods in intestinal development and homeostasis. Am. J. Physiol. Gastrointest. Liver Physiol. 292, G6-G10 (2007).

3. Rakoff-Nahoum, S., Paglino, J., Eslami-Varzaneh, F., Edberg, S. \& Medzhitov, R. Recognition of commensal microflora by Toll-like receptors is required for intestinal homeostasis. Cell 118, 229-241 (2004).

4. Shibolet, O.\& Podolsky, D.K. TLRs in the gut. IV. Negative regulation of Toll-like receptors and intestinal homeostasis: addition by subtraction. Am. J. Physiol. Gastrointest. Liver Physiol. 292, G1469-G1473 (2007).

5. Karrasch, T., Kim, J.S., Muhlbauer, M., Magness, S.T. \& Jobin, C. Gnotobiotic IL-10-1-;NF-kappa B(EGFP) mice reveal the critical role of TLR/NF-kappa B signaling in commensal bacteria-induced colitis. J. Immunol. 178, 6522-6532 (2007).

6. Lotz, M., Gutle, D., Walther, S., Menard, S., Bogdan, C. \& Hornef, M.W. Postnatal acquisition of endotoxin tolerance in intestinal epithelial cells. J. Exp. Med. 203, 973-984 (2006).

7. Abreu, M.T., Vora, P., Faure, E., Thomas, L.S., Arnold, E.T. \& Arditi, M. Decreased expression of Toll-like receptor- 4 and MD-2 correlates with intestinal epithelial cell protection against dysregulated proinflammatory gene expression in response to bacterial lipopolysaccharide. J. Immunol. 167, 1609-1616 (2001).

8. Cario, E., Golenbock, D.T., Visintin, A., Runzi, M., Gerken, G. \& Podolsky, D.K. Trypsin-sensitive modulation of intestinal epithelial MD-2 as mechanism of lipopolysaccharide tolerance. J. Immunol. 176, 4258-4266 (2006).

9. Lenoir, C. et al. MD-2 controls bacterial lipopolysaccharide hyporesponsiveness in human intestinal epithelial cells. Life Sci. 82, 519-528 (2008).

10. Didierlaurent, A. et al. Tollip regulates proinflammatory responses to interleukin-1 and lipopolysaccharide. Mol. Cell Biol. 26, 735-42 (2006).
11. Otte, J.M., Cario, E. \& Podolsky, D.K. Mechanisms of cross hyporesponsiveness to Toll-like receptor bacterial ligands in intestinal epithelial cells. Gastroenterology 126, 1054-1070 (2004).

12. Sun, J., Fegan, P.E., Desai, A.S., Madara, J.L. \& Hobert, M.E. Flagellininduced tolerance of the Toll-like receptor 5 signaling pathway in polarized intestinal epithelial cells. Am. J. Physiol. Gastrointest. Liver Physiol. 292, G767-G778 (2007)

13. Gewirtz, A.T., Navas, T.A., Lyons, S., Godowski, P.J. \& Madara, J.L. Cutting edge: bacterial flagellin activates basolaterally expressed TLR5 to induce epithelial proinflammatory gene expression. J. Immunol. 167, 1882-1885 (2001).

14. Cario, E., Brown, D., McKee, M., Lynch-Devaney, K., Gerken, G. \& Podolsky, D.K. Commensal-associated molecular patterns induce selective Toll-like receptor-trafficking from apical membrane to cytoplasmic compartments in polarized intestinal epithelium. Am. J. Pathol. 160, 165-173 (2002).

15. Lee, J. et al. Maintenance of colonic homeostasis by distinctive apical TLR9 signaling in intestinal epithelial cells. Nat. Cell Biol. 8, 1327-1336 (2006).

16. Wang, J., Ouyang, Y., Guner, Y., Ford, H.R. \& Grishin, A.V. Ubiquitinediting enzyme A20 promotes tolerance to lipopolysaccharide in enterocytes. J. Immunol. 183, 1384-1392 (2009).

17. Boone, D.L. et al. The ubiquitin-modifying enzyme $\mathrm{A} 20$ is required for termination of Toll-like receptor responses. Nat. Immunol. 5, 1052-1060 (2004).

18. Turer, E.E. et al. Homeostatic MyD88-dependent signals cause lethal inflammation in the absence of A20. J. Exp. Med. 205, 451-464 (2008).

19. Grishin, A. et al. p38 MAP kinase mediates endotoxin-induced expression of cyclooxygenase-2 in enterocytes. Surgery 136, 329-335 (2004).

20. Grishin, A.V. et al. Lipopolysaccharide induces cyclooxygenase-2 in intestinal epithelium via a noncanonical p38 MAPK pathway. J. Immunol. 176, 580-588 (2006).

21. Akhtar, M., Watson, J.L., Nazli, A. \& McKay, D.M. Bacterial DNA evokes epithelial IL-8 production by a MAPK-dependent, NF-kappaBindependent pathway. FASEB J. 17, 1319-1321 (2003).

22. Khan, M.A., Kang, J. \& Steiner, T.S. Enteroaggregative Escherichia coli flagellin-induced interleukin-8 secretion requires Toll-like receptor 5 dependent p38 MAP kinase activation. Immunology 112, 651-660 (2004).

23. Wang, X. \& Liu, Y. Regulation of innate immune response by MAP kinase phosphatase-1. Cell Signal 19, 1372-1382 (2007).

24. Vogt, A., Tamewitz, A., Skoko, J., Sikorski, R.P., Giuliano, K.A. \& Lazo, J.S. The benzo[c]phenanthridine alkaloid, sanguinarine, is a selective, cell-active inhibitor of mitogen-activated protein kinase phosphatase-1. J. Biol. Chem. 280, 19078-19086 (2005).

25. Jang, B.C. et al. Sanguinarine induces apoptosis in A549 human lung cancer cells primarily via cellular glutathione depletion. Toxicol. In Vitro 23 , 281-287 (2009).

26. Shepherd, E.G., Zhao, Q., Welty, S.E., Hansen, T.N., Smith, C.V. \& Liu, Y. The function of mitogen-activated protein kinase phosphatase- 1 in peptidoglycan-stimulated macrophages. J. Biol. Chem. 279, 54023-54031 (2004).

27. Zhao, Q. et al. MAP kinase phosphatase 1 controls innate immune responses and suppresses endotoxic shock. J. Exp. Med. 203, 131-140 (2006).

28. Chen, P., Li, J., Barnes, J., Kokkonen, G.C., Lee, J.C. \& Liu, Y. Restraint of proinflammatory cytokine biosynthesis by mitogen-activated protein kinase phosphatase- 1 in lipopolysaccharide-stimulated macrophages. J. Immunol. 169, 6408-6416 (2002).

29. Xiao, Y.Q. et al. Cross-talk between ERK and p38 MAPK mediates selective suppression of pro-inflammatory cytokines by transforming growth factor-beta. J. Biol. Chem. 277, 14884-14893 (2002).

30. Sanchez-Tillo, E. et al. JNK1 is required for the induction of MKP-1 expression in macrophages during proliferation and lipopolysaccharidedependent activation. J. Biol. Chem. 282, 12566-12573 (2007).

31. Breitwieser, W. et al. Feedback regulation of p38 activity via ATF2 is essential for survival of embryonic liver cells. Genes Dev. 21, 2069-2082 (2007).

32. Hu, J.H. et al. Feedback control of MKP-1 expression by p38. Cell Signal 19, 393-400 (2007).

33. Kim, S.M. et al. Cadmium specifically induces MKP-1 expression via the glutathione depletion-mediated p38 MAPK activation in C6 glioma cells. Neurosci. Lett. 440, 289-293 (2008). 


\section{ARTICLES}

34. Lasa, M., Abraham, S.M., Boucheron, C., Saklatvala, J. \& Clark, A.R. Dexamethasone causes sustained expression of mitogen-activated protein kinase (MAPK) phosphatase 1 and phosphatase-mediated inhibition of MAPK p38. Mol. Cell Biol. 22, 7802-7811 (2002).

35. Wang, Z., Cao, N., Nantajit, D., Fan, M., Liu, Y. \& Li, J.J. Mitogenactivated protein kinase phosphatase-1 represses c-Jun NH2-terminal kinase-mediated apoptosis via NF-kappaB regulation. J. Biol. Chem. 283, 21011-21023 (2008).

36. De Plaen, I.G. et al. Endotoxin, but not platelet-activating factor, activates nuclear factor-kappaB and increases IkappaBalpha and IkappaBbeta turnover in enterocytes. Immunology 106, 577-583 (2002).

37. Kwak, S.P., Hakes, D.J., Martell, K.J. \& Dixon, J.E. Isolation and characterization of a human dual specificity protein-tyrosine phosphatase gene. J. Biol. Chem. 269, 3596-3604 (1994).

38. Li, J., Gorospe, M., Hutter, D., Barnes, J., Keyse, S.M. \& Liu, Y. Transcriptional induction of MKP-1 in response to stress is associated with histone $\mathrm{H} 3$ phosphorylation-acetylation. Mol. Cell Biol. 21, 8213-8224 (2001).

39. Chi, H. et al. Dynamic regulation of pro- and anti-inflammatory cytokines by MAPK phosphatase 1 (MKP-1) in innate immune responses. Proc. Natl Acad. Sci. USA 103, 2274-2279 (2006).

40. Salojin, K.V., Owusu, I.B., Millerchip, K.A., Potter, M., Platt, K.A. \& Oravecz, T. Essential role of MAPK phosphatase- 1 in the negative control of innate immune responses. J. Immunol. 176, 1899-1907 (2006).

41. Wang, X. et al. Knockout of MKP-1 enhances the host inflammatory responses to gram-positive bacteria. J. Immunol. 178:5312-5320 (2007).

42. Hammer, M. et al. Dual specificity phosphatase 1 (DUSP1) regulates a subset of LPS-induced genes and protects mice from lethal endotoxin shock. J. Exp. Med. 203, 15-20 (2006).
43. Zhao, Q., Shepherd, E.G., Manson, M.E., Nelin, L.D., Sorokin, A. \& Liu, Y. The role of mitogen-activated protein kinase phosphatase- 1 in the response of alveolar macrophages to lipopolysaccharide: attenuation of proinflammatory cytokine biosynthesis via feedback control of p38. J. Biol. Chem. 280, 8101-8108 (2005).

44. King, E.M., Holden, N.S., Gong, W., Rider, C.F. \& Newton, R. Inhibition of NF-kappaB-dependent transcription by MKP-1: transcriptional repression by glucocorticoids occurring via p38 MAPK. J. Biol. Chem. 284, 26803-26815 (2009).

45. Cario, E., Gerken, G. \& Podolsky, D.K. Toll-like receptor 2 controls mucosal inflammation by regulating epithelial barrier function. Gastroenterology 132, 1359-1374 (2007).

46. Yu, Y. et al. TLR5-mediated activation of p38 MAPK regulates epithelial IL-8 expression via posttranscriptional mechanism. Am. J. Physiol. Gastrointest. Liver Physiol. 285, G282-G290 (2003).

47. Egan, L.J., de Lecea, A., Lehrman, E.D., Myhre, G.M., Eckmann, L. \& Kagnoff, M.F. Nuclear factor-kappa B activation promotes restitution of wounded intestinal epithelial monolayers. Am. J. Physiol. Cell Physiol. 285, C1028-C1035 (2003).

48. Inan, M.S., Tolmacheva, V., Wang, Q.S., Rosenberg, D.W. \& Giardina, C. Transcription factor NF-kappaB participates in regulation of epithelial cell turnover in the colon. Am. J. Physiol. Gastrointest. Liver Physiol. 279, G1282-G1291 (2000).

49. Steinbrecher, K.A., Harmel-Laws, E., Sitcheran, R. \& Baldwin, A.S. Loss of epithelial RelA results in deregulated intestinal proliferative/ apoptotic homeostasis and susceptibility to inflammation. J. Immunol. 180, 2588-2599 (2008).

50. Nenci, A. et al. Epithelial NEMO links innate immunity to chronic intestinal inflammation. Nature 446, 557-561 (2007).

51. Zaph, C. et al. Epithelial-cell-intrinsic IKK-beta expression regulates intestinal immune homeostasis. Nature 446, 552-556 (2007). 